\title{
Development of a Flow Cytometry Live Cell Assay for the Screening of Inhibitors of Hepatitis C Virus (HCV) Replication
}

\author{
Jose A. Garcia-Rivera ${ }^{1}$, Kai Lin $^{2}$, Sam Hopkins ${ }^{3}$, Matthew A. Gregory ${ }^{4}$, Barrie Wilkinson ${ }^{4}$ and \\ Philippe A. Gallay ${ }^{*}, 1$ \\ ${ }^{I}$ Department of Immunology \& Microbial Science, The Scripps Research Institute, La Jolla, California 92037, USA \\ ${ }^{2}$ Novartis Institutes for Biomedical Research, Inc., Cambridge, USA \\ ${ }^{3}$ SCYNEXIS, Inc., Research Triangle Park, USA \\ ${ }^{4}$ Biotica Technology Ltd, Chesterford Research Park, Cambridge, CB10 1XL, UK
}

\begin{abstract}
In this study, we established a flow cytometry live cell-based assay that permits the screening of hepatitis $\mathrm{C}$ virus (HCV) inhibitors. Specifically, we created a stable cell line, which harbors a subgenomic replicon encoding an NS5A-YFP fusion protein. This system allows direct measurement of YFP fluorescence in live hepatoma cells in which the $\mathrm{HCV}$ replicon replicates. We demonstrated that this stable fluorescent system permits the rapid and sensitive quantification of HCV replication inhibition by direct-acting antiviral agents (DAA) including protease and NS5A inhibitors and host-targeting antiviral agents (HTA) including cyclophilin inhibitors. This flow cytometry-based live cell assay is well suited for multiple applications such as the evaluation of HCV replication as well as antiviral drug screening.
\end{abstract}

Keywords: Direct-acting antiviral, FACS assay, HCV, hepatoma cells, host-targeting antiviral, inhibitors.

\section{INTRODUCTION}

$\mathrm{HCV}$ is the major causative agent of acute and chronic liver diseases [1]. Nearly 200 million people worldwide (3\% of the population), including 4 to 5 million in the US, are chronically infected with HCV and 4 million new infections occur every year [2,3]. In the developed world, HCV accounts for two-thirds of all cases of liver cancer and transplants [4], and in the US, approximately 12,000 people are estimated to die from HCV each year [5].

The introduction of IFN $\alpha$ and the nucleoside analog ribavirin (RBV) greatly improved the percentage of chronically HCV-infected patients able to reach a sustained antiviral response (SVR) [6,7]. Yet, the current standard PEGylated IFN $\alpha$ plus RBV (pIFN $\alpha /$ RBV) therapy has a low success rate of approximately $50 \%$ in patients with genotype $1 \mathrm{HCV}[8,9]$ and can be associated with significant side effects [10]. Not only is genotype 1 the most prevalent HCV genotype in Europe, North and South America, China and Japan, it is also the most difficult to treat [11]. Thus, there is an urgent need for the development of additional anti-HCV agents with novel mechanisms of antiviral action in order to provide alternate treatments for the increasing number of patients who are unresponsive to the current $\mathrm{pIFN \alpha /RBV}$ treatment $[2,12]$.

The availability of assays, which permit the identification of new anti-HCV agents, is limited. Two main assays were

*Address correspondence to this author at the Department of Immunology \& Microbial Science, IMM-9, The Scripps Research Institute, $10550 \mathrm{~N}$. Torrey Pines Rd., La Jolla, CA 92037, USA; Tel: (858) 784-8180; Fax: (858) 784-8831; E-mail: gallay@scripps.edu developed for the precise quantification of HCV replicon replication and for the discovery of antivirals: a real-time RT-PCR assay and a luciferase-based reporter assay $[13,14]$. Although these systems have proven to be vital in understanding many aspects of $\mathrm{HCV}$ replication, their main disadvantage is cost, both RT-PCR and luciferase reagents are expensive. In this study, we developed a rapid, sensitive and reproducible flow cytometry-based assay, which permits the identification of new anti-HCV agents in live cells in a quantitative manner to complement the existing $\mathrm{HCV}$ replicon replication assays currently available.

\section{MATERIALS AND METHODS}

\subsection{FACS Assay Development Summary}

To develop this assay, we generated a stable hepatoma cell line harboring a fluorescent Con1 subgenomic replicon Luc-Con1-NS5A-YFP. This stable cell line was treated with a panel of anti-HCV compounds and viral replication was measured via FACS analysis between a period of 24-96 hrs.

\subsection{Plasmid}

The Luc-Con1-NS5A-YFP vector was established by the insertion of the yellow fluorescent protein (YFP) into the Cterminus of the NS5A gene (MVSKGEELF-YFP-TLGMDE LYK) via homologous recombination using the In-Fusion HD Cloning kit (Clontech). Specifically, we inserted the yellow fluorescent protein (YFP) in the C-terminal region of NS5A in the HCV Luc-Con1 genome (pFKI389Luc-Ubineo/NS3-3'/ET) (Fig. 1A) in the same way the green fluorescent protein (GFP) had previously been inserted into the NS5A gene [15-18]. The resulting plasmid was called Luc-Con1-NS5A-YFP. 


\subsection{Cell Line}

The Huh 7.5.1 Luc-Con1-NS5A-YFP stable cell line was achieved via electroporation of Luc-Con1-NS5A-YFP RNA into the Huh 7.5.1 hepatoma cell line. In brief, RNA was synthesized from SpeI linearized Luc-Con1-NS5A-YFP DNA using the T7 MEGAscript kit (Ambion), 4x10 ${ }^{6}$ Huh 7.5.1 cells were electroporated with $10 \mu \mathrm{g}$ of RNA and G-418 selected $(50 \mu \mathrm{g} / \mathrm{ml})$ for 3 weeks. Huh 7.5.1 Luc-Con1-NS5AYFP cells were enriched using the BD FACS Aria sorter (Fig. 1B).

\subsection{FACS Analysis}

500,000 Huh 7.5.1 Luc-Con1-NS5A-YFP cells were seeded, HCV inhibitors were added one day post-seeding and replication was analyzed via FACS 1, 2, 3 and 4 days post-drug treatment. Cells were trypsonized, washed twice with PBS1X, and resuspended in $500 \mu 1$ of Sorting Buffer (PBS1X supplemented with 1mM EDTA, 25mM HEPES $\mathrm{pH}$ 7.0 , and $1 \%$ FBS). FACS analysis was performed using the BD $^{\mathrm{TM}}$ LSR II Flow Cytometer System and FACSDiva software. Gates for the FITC-A and Pacific Blue channels were set using parental Huh 7.5.1 cells as negative control and YFP expression was measured within the FITC-A positive gate. Results were all normalized to DMSO controls.

\subsection{Luciferase}

100,000 Huh 7.5.1 Luc-Con1-NS5A-YFP cells were seeded, HCV inhibitors were added one day post-seeding and replication was analyzed via luciferase activity 1-3 days post-drug treatment. Cells were washed twice with PBS1X, and lysed in $100 \mu$ l of cell culture lysis reagent (Promega). $30 \mu \mathrm{l}$ of each lysate were used for the analysis and all results were normalized to DMSO controls.

\subsection{Confocal Analysis}

Live Luc-Con1-NS5A-YFP Huh-7.5.1 cells were fixed in $4 \%(\mathrm{w} / \mathrm{v})$ paraformaldehyde. Cells were examined with a Zeiss LSM 710 laser scanning confocal microscope using $63 \mathrm{x}$ objective with the $488 \mathrm{~nm}$ laser to detect NS5A YFP, nuclei were visualized using DAPI staining. Images were analyzed using the Zeiss Zen software.

\subsection{Immunoblotting}

Cellular lysates were resolved by SDS-PAGE and transferred $1 \mathrm{hr}$ onto polyvinylidene difluoride (PDVF) membranes at $100 \mathrm{~V}$. Membranes were blocked with Trisbuffered saline (TBS) containing 10\% milk for $1 \mathrm{hr}$ and then incubated with the corresponding primary antibody diluted in TBS-5\% milk-0.05\% Tween 20 (antibody dilution buffer). NS5A-YFP was detected with anti-GFP polyclonal IgG (1/1000, Santa Cruz Biotechnology), NS5B with antiNS5B monoclonal IgG (1/1000, Enzo Life Sciences), CypA with anti-CypA polyclonal IgG (1/1000, [19]), CypB with anti-CypB mAb (1/1000, Zymed Laboratories) and calnexin with anti-calnexin polyclonal IgG (1/5000, Sigma Life Sciences).

\section{RESULTS}

We found that both Luc-Con1 and Luc-Con1-NS5A-YFP cell lines efficiently replicated the viral genome as demonstrated by high and sustained luciferase levels over a period of one month and behaved in nearly identical manners when titrated with Alisporivir (Fig. 1C, D). This further suggests that the YFP insertion into the NS5A gene does not significantly alter the replication of the replicon. Second, we used confocal microscopy to analyze the expression of the NS5A-YFP protein in cells harboring the Luc-Con1-NS5AYFP replicon. The YFP fluorescence signal was found in the cytoplasm as bright dots in a reticular staining pattern that surrounds the nucleus that likely represents the endoplasmic reticulum (ER) compartment (Fig. 1E). This pattern is similar to the distribution of HCV nonstructural proteins in Huh-7 cells harboring subgenomic HCV replicons, as determined by immunofluorescence microscopy [20]. Taken together, the similarity of size, distribution, and morphology of the dot-like YFP structures identified here with those previously identified as HCV RNA replication complexes, strongly suggests that the NS5A-YFP fusion protein is incorporated into such complexes.

We then assessed whether the established Luc-Con1NS5A-YFP replicon cell line permits the screening of antiviral agents. We selected a panel of anti-HCV compounds including direct-acting (DAA) and host-targeting antivirals (HTA). As DAA, we chose the recently FDAapproved protease inhibitor telaprevir [21,22] and the potent investigational NS5A inhibitor, BMS-790052, which is currently in phase II studies [23]. As HTA agents, we chose cyclophilin inhibitors such as cyclosporine A (CsA) [24], two non-immunosuppressive CsA analogs: Alisporivir [25] and SCY-635 [26] as well as sanglifehrin A (SfA) and one SfA analog: BC544 [27]. Alisporivir and SCY-635 are currently being tested for safety and efficacy in phase III and II studies, respectively, whilst BC544 is in preclinical development.

Efficacy of the selected compounds was first examined by luciferase production in lysates of Luc-Con1-NS5A-YFP replicon cells 3 days post-drug exposure. The $50 \%$ effective concentrations $\left(\mathrm{EC}_{50}\right)$ for inhibition of Luc-Con1-NS5AYFP replication in Huh-7.5.1 cells by telaprevir, BMS790052, CsA, Alisporivir, SCY-635, SfA, BC544 and BC556 were $8.1 \pm 1.4,1.4 \pm 0.2,311 \pm 23,7.9 \pm 0.4,8.2 \pm$ $1.1,288 \pm 33,6.1 \pm 1.2$ and $5.4 \pm 0.6 \mathrm{nM}$, respectively (Table 1). Except for CsA, a majority of the drugs exhibit low cytotoxicity $\left(\mathrm{CC}_{50}>10 \mu \mathrm{M}\right)$ (Table 1). After verifying high antiviral activities of the selected compounds using luciferase as the reporter gene, we examined their potency using NS5A-YFP as the reporter gene by flow cytometry. Stable Luc-Con1-NS5A-YFP replicon cells were exposed to control (DMSO) or selected drugs and analyzed by FACS for YFP content. Parental Huh-7.5.1 cells express minimal autofluorescence $(0.3 \%)$, whereas Luc-Con1-NS5A-YFP cells exhibit a strong YFP signal (81.2\%). All drugs when used at a concentration of $2 \mu \mathrm{M}$ and their antiviral activity assessed between a 24-96 $\mathrm{hr}$ period reduced the percentage of YFP+ cells, indicating that they efficiently block HCV RNA replication. Specifically, at the $72 \mathrm{hr}$ time point the percentage of YFP+ cells was reduced from $81.2 \%$ to $1.22 \%$ for telaprevir, 2.42\% for BMS-790052, 3.94\% for CsA, 5.3\% for Alisporivir, $1.77 \%$ for SCY-635, 33.5\% for SfA, and $9.36 \%$ for BC544 (Fig. 2A). There is thus a direct correlation for antiviral potency as measured by luciferase in cell lysates and YFP fluorescence in live cells. 
A

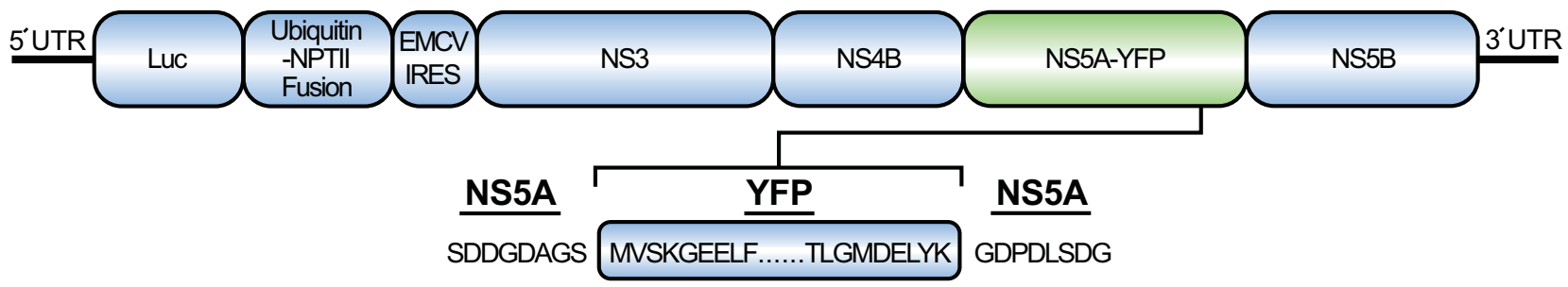

B
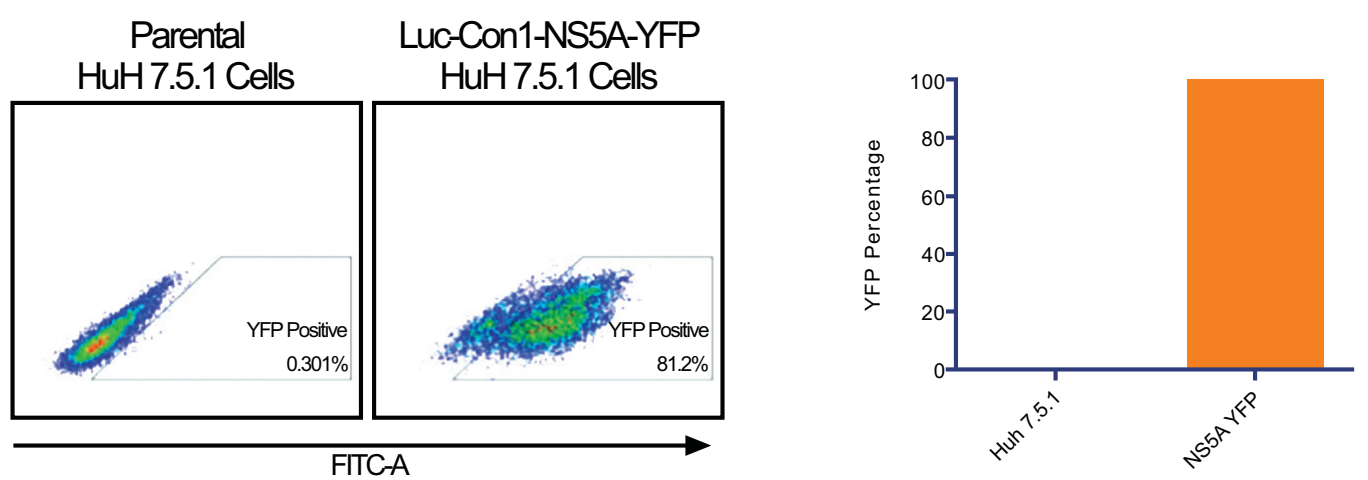

C

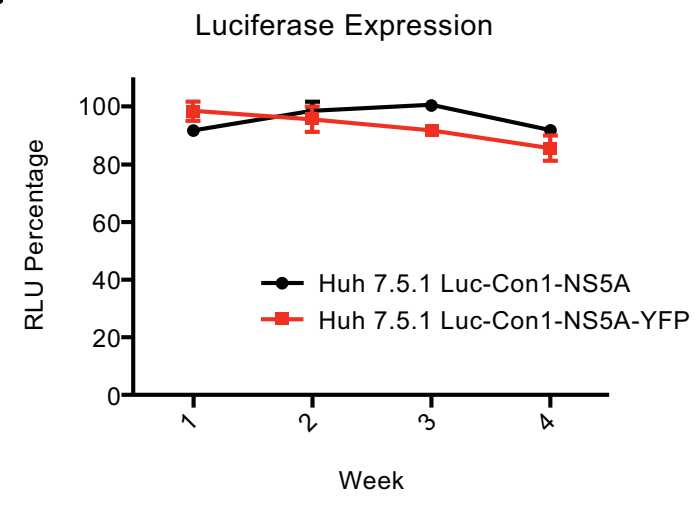

E
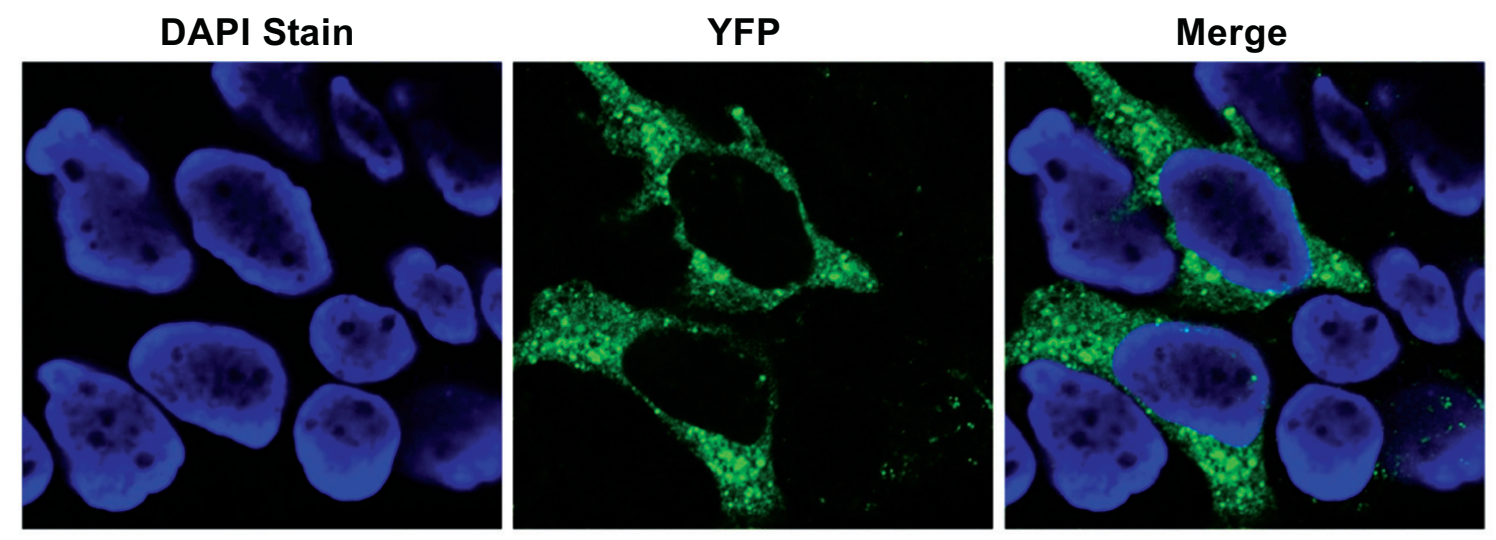

Fig. (1). Establishment of a stable Luc-Con1-NS5A-YFP subgenomic replicon cell line. A. Schematic diagram of the dual luciferase/YFP reporter subgenomic Con1 replicon. B. The YFP-positive cell population was enriched using the BD FACSAria sorter. C. Sustained replication of the sub-genomic replicon measured via luciferase in Huh 7.5.1 Luc-Con1-NS5A-YFP cells over the period of one month is nearly identical to Huh 7.5.1 Luc-Con1-NS5A cells. D. Titration of Alisporivir in Huh 7.5.1 Luc-Con1-NS5A YFP cells demonstrates a direct correlation between luciferase and YFP levels, $t$ tests conducted between both data sets indicate no statistical significant difference, in each data set $\mathrm{P}>0.05$. Error bars represent SD. E. Luc-Con1-NS5A-YFP Huh-7.5.1 cells were visualized via confocal analysis 5 days post drug treatment with Alisporivir $(2 \mu \mathrm{M})$ and SCY-635 $(2 \mu \mathrm{M})$. 
Table 1. Inhibitory and Cytotoxic Effects of Antivirals on Luc-Con1-NS5A-YFP Subgenomic Replicon Replication

\begin{tabular}{|c|c|c|}
\hline Treatment & $\mathbf{E C}_{\mathbf{5 0}}(\mathbf{n M})$ & $\mathbf{C C}_{\mathbf{5 0}}(\mathbf{I}$ M) \\
\hline \hline Telaprevir & 8.1 & $>20$ \\
\hline BMS-790052 & 1.4 & $>20$ \\
\hline CsA & 311 & 4.9 \\
\hline Alisporivir & 7.9 & $>20$ \\
\hline SCY-635 & 8.2 & $>20$ \\
\hline SfA & 288 & 10.1 \\
\hline BC544 & 6.1 & $>20$ \\
\hline
\end{tabular}

$\mathrm{EC}_{50}$ is the concentration of drugs required to reduce the replicon content in Huh7.5.1 cells by $50 \%$ as measured by luciferase activity in cell lysates. $\mathrm{CC}_{50}$ is the concentration of drug required to inhibit cell proliferation by $50 \%$ as determined by an MTS assay. $\mathrm{EC}_{50}$ and $\mathrm{CC}_{50}$ were determined as previously described [28]. Results are representative of 3 independent experiments.

Kinetic studies indicate that the percentage of YFP+ cells 2 days post-drug exposure is already reduced (Fig. 2B), but 3 days post-drug treatment, all compounds, except SfA, dramatically reduced the YFP fluorescence signal (Fig. 2B), demonstrating the high potency of the selected compounds. Results were unchanged 4 days post-drug treatment (Fig. 2B), suggesting that the inhibitory action of the selected antivirals reaches a maximal effect after 3 days. Titration studies using the cyclophilin inhibitor Alisporivir as an antiviral prototype demonstrate that the flow cytometrybased live cell assay represents a useful tool to quantitatively screen HCV inhibitors (Fig. 2C). We verified the FACS results (Fig. 2B) by confocal analysis. Exposure of LucCon1-NS5A-YFP cells to cyclophilin inhibitors such as Alisporivir and SCY-635 totally abolished the YFP fluorescence signal compared to the control (Fig. 2D). We also verified the block of viral replication by examining HCV protein levels in Luc-Con1-NS5A-YFP cells by Western blotting. NS5A-YFP levels were profoundly reduced 2 and 3 days post-drug treatment (Fig. 2E). Similar results were obtained for NS5B (Fig. 2E). Interestingly, an NS5B signal was still detectable three days post-SfA treatment (Fig. 2E), correlating well with residual YFP levels detected by flow cytometry in SfA-treated live cells (Fig. 2B). Similar levels of calnexin and cyclophilin A
A
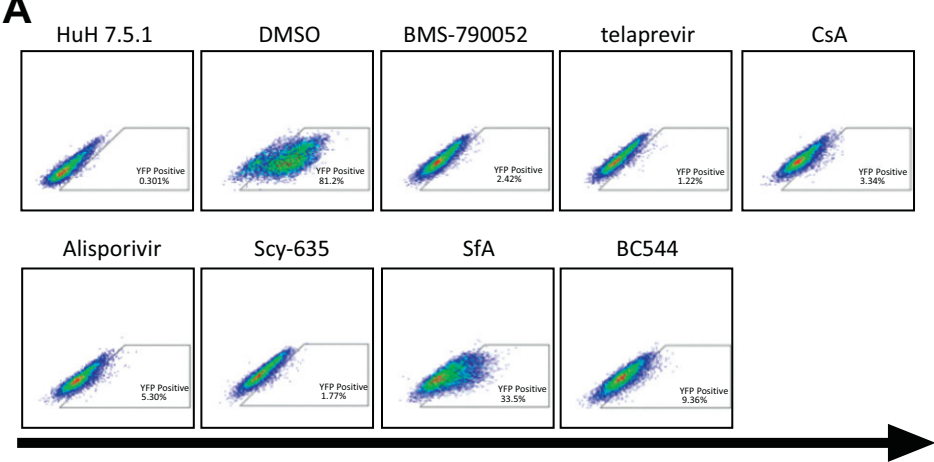

YFP (488)

D
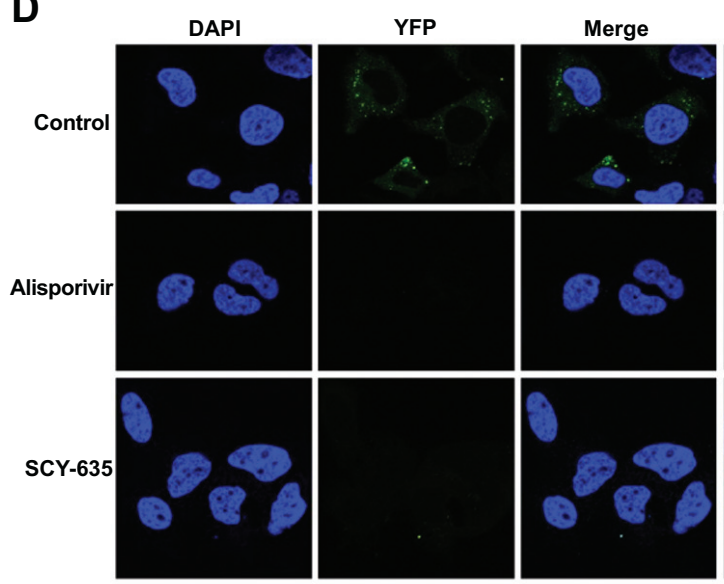

Enlarged

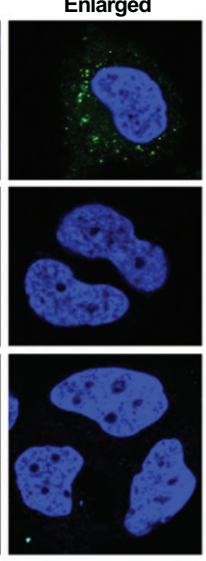

B

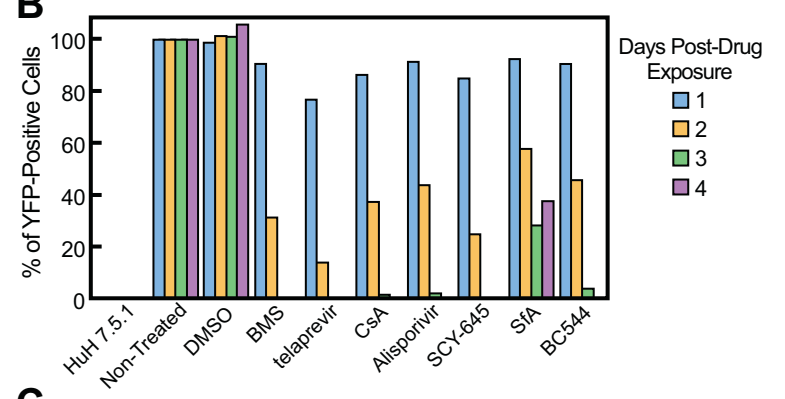

C

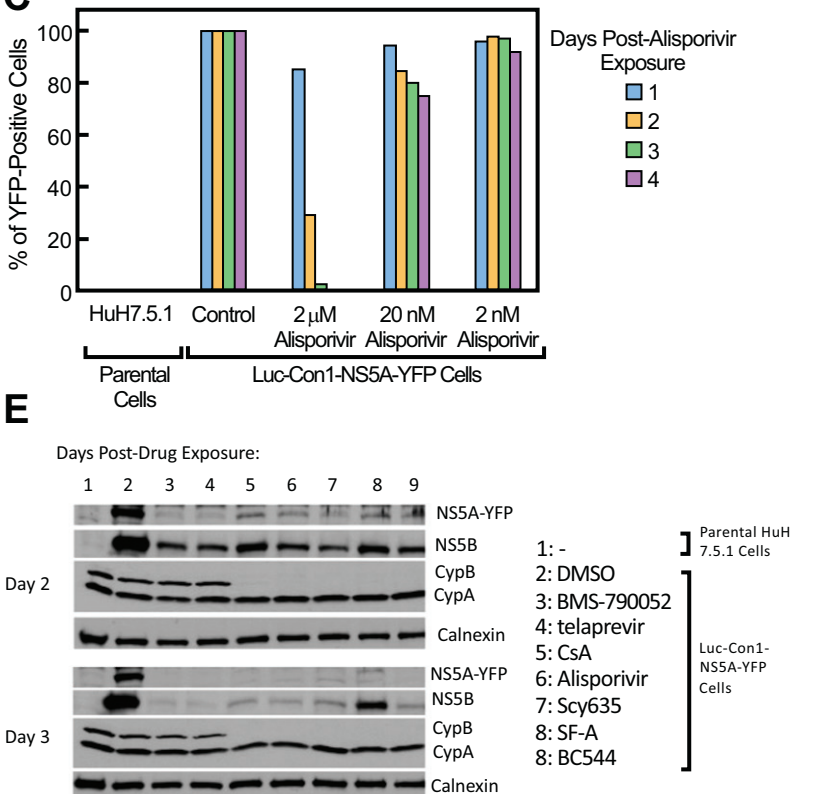

Fig. (2). Screening of inhibitors of HCV replication using the flow cytometry live cell-based assay. A. Luc-Con1-NS5A-YFP Huh-7.5.1 cells $(500,000)$ were exposed to anti-HCV agents $(2 \mu \mathrm{M})$ and analyzed for YFP content 3 days post-drug treatment. B. Same as A except that cells were analyzed for YFP content after days 1, 2, 3 and 4. C. Same as B except that the drug was used at 3 concentrations: 2, 0.2 and 0.2 $\mu \mathrm{M}$. Results (A-C) are representative of 3 independent experiments. D. Same as 1B. E. Same as 2A except that 2 and 3 days post-drug exposure cells were lysed and analyzed for viral and host protein content by Western blotting as described previously [31]. 
(CypA) indicate that similar levels of proteins were analyzed (Fig. 2E). Intracellular cyclophilin B (CypB) levels were dramatically reduced in Huh-7.5.1 cells treated with all cyclophilin inhibitors (CsA, Alisporivir, SCY-635, SfA or BC544), but not with non-cyclophilin inhibitors (telaprevir and BMS-790052) (Fig. 2E). These data are in accordance with previous findings including ours that cyclophilin inhibitors such as CsA and Alisporivir, by binding to the enzymatic hydrophobic pocket of CypB, trigger the release of CypB from the ER into the extracellular medium $[29,30]$.

\section{DISCUSSION}

In this study, we established a flow cytometry live cellbased assay that permits a rapid and sensitive screening of HCV inhibitors. Specifically, we created a stable cell line, which harbors a subgenomic replicon encoding an NS5AYFP fusion protein. This system allows direct and sensitive measure of YFP fluorescence in live hepatoma cells, which support autonomous viral RNA replication and viral protein expression from the HCV replicon. Importantly, this flow cytometry system is not only fast, but it also exhibits an extremely low variability between assays. Furthermore, we demonstrated that this stable fluorescent system permits the precise quantification of $\mathrm{HCV}$ replication inhibition by mechanistically distinct classes of inhibitors including directacting (DAA) and host-targeting antiviral (HTA) agents. In conclusion, this flow cytometry live cell-based assay is well suited for multiple applications including the evaluation of $\mathrm{HCV}$ replication and anti-HCV drug screening.

\section{CONFLICT OF INTEREST}

The authors confirm that this article content has no conflict of interest.

\section{ACKNOWLEDGEMENTS}

We thank Francis Chisari and Ralph Bartenschlager for the Huh-7.5.1. cells and the pFKI389Luc-Ubineo/NS3-3'/ET plasmid, respectively. BMS-790052, telaprevir, SfA and BC544 were obtained from Biotica, Alisporivir from Novartis and SCY-635 from Scynexis Inc. J. A. GarciaRivera is supported by U.S. Public Health Service Kirschstein Institutional National Research Service Award no. AI007354. We acknowledge financial support from the U.S. Public Health Service grant no. AI087746 (P.A.G.). This is publication no. 21341 from the Department of Immunology \& Microbial Science, The Scripps Research Institute, La Jolla, CA.

\section{REFERENCES}

[1] Dienstag JL, McHutchison JG. American Gastroenterological Association technical review on the management of hepatitis $\mathrm{C}$. Gastroenterology 2006; 130(1): 231-64; quiz 14-7.

[2] Alter MJ. Epidemiology of hepatitis C virus infection. World J Gastroenterol 2007; 13(17): 2436-41.

[3] Soriano V, Madejon A, Vispo E, et al. Emerging drugs for hepatitis C. Expert Opin Emerg Drugs 2008; 13(1): 1-19.

[4] Shepard CW, Finelli L, Alter MJ. Global epidemiology of hepatitis C virus infection. Lancet Infect Dis 2005; 5(9): 558-67.

[5] Armstrong GL, Wasley A, Simard EP, McQuillan GM, Kuhnert WL, Alter MJ. The prevalence of hepatitis $C$ virus infection in the United States, 1999 through 2002. Ann Intern Med 2006; 144(10): 705-14.

[6] Tong MJ, Reddy KR, Lee WM, et al. Treatment of chronic hepatitis $\mathrm{C}$ with consensus interferon: a multicenter, randomized, controlled trial. Consensus Interferon Study Group. Hepatology 1997; 26(3): 747-54.

[7] Sy T, Jamal MM. Epidemiology of hepatitis C virus (HCV) infection. Int J Med Sci 2006; 3(2): 41-6.

[8] Simmonds P, Bukh J, Combet C, et al. Consensus proposals for a unified system of nomenclature of hepatitis $\mathrm{C}$ virus genotypes. Hepatology 2005; 42(4): 962-73.

[9] Cross TJ, Antoniades CG, Harrison PM. Current and future management of chronic hepatitis C infection. Postgrad Med J 2008; 84(990): 172-6.

[10] Manns MP, Wedemeyer H, Cornberg M. Treating viral hepatitis C: efficacy, side effects, and complications. Gut 2006; 55(9): 1350-9.

[11] Global surveillance and control of hepatitis C. Report of a WHO Consultation organized in collaboration with the Viral Hepatitis Prevention Board, Antwerp, Belgium. J Viral Hepat 1999; 6(1): 3547.

[12] Davis GL, Albright JE, Cook SF, Rosenberg DM. Projecting future complications of chronic hepatitis $\mathrm{C}$ in the United States. Liver Transpl 2003; 9(4): 331-8.

[13] Lee JC, Chang CF, Chi YH, Hwang DR, Hsu JT. A reporter-based assay for identifying hepatitis $\mathrm{C}$ virus inhibitors based on subgenomic replicon cells. J Virolog Methods 2004; 116(1): 27-33.

[14] Krieger N, Lohmann V, Bartenschlager R. Enhancement of hepatitis C virus RNA replication by cell culture-adaptive mutations. J Virol 2001; 75(10): 4614-24.

[15] Moradpour D, Evans MJ, Gosert R, et al. Insertion of green fluorescent protein into nonstructural protein $5 \mathrm{~A}$ allows direct visualization of functional hepatitis $\mathrm{C}$ virus replication complexes. J Virol 2004; 78(14): 7400-9.

[16] Jones DM, Gretton SN, McLauchlan J, Targett-Adams P. Mobility analysis of an NS5A-GFP fusion protein in cells actively replicating hepatitis C virus subgenomic RNA. J Gen Virol 2007; 88(Pt 2): 470-5.

[17] Kim CS, Jung JH, Wakita T, Yoon SK, Jang SK. Monitoring the antiviral effect of alpha interferon on individual cells. J Virol 2007; 81(16): 8814-20.

[18] Schaller T, Appel N, Koutsoudakis G, et al. Analysis of hepatitis C virus superinfection exclusion by using novel fluorochrome genetagged viral genomes. J Virol 2007; 81(9): 4591-603.

[19] Chatterji U, Bobardt M, Selvarajah S, et al. The isomerase active site of cyclophilin A is critical for hepatitis $\mathrm{C}$ virus replication. J Biol Chem 2009; 284(25): 16998-7005.

[20] Gosert R, Egger D, Lohmann V, et al. Identification of the hepatitis $\mathrm{C}$ virus RNA replication complex in Huh-7 cells harboring subgenomic replicons. J Virol 2003; 77(9): 5487-92.

[21] Zeuzem S, Andreone P, Pol S, et al. Telaprevir for retreatment of HCV infection. N Eng J Med 2011; 364(25): 2417-28.

[22] Jacobson IM, McHutchison JG, Dusheiko G, et al. Telaprevir for previously untreated chronic hepatitis $\mathrm{C}$ virus infection. $\mathrm{N}$ Eng $\mathrm{J}$ Med 2011; 364(25): 2405-16.

[23] Gao M, Nettles RE, Belema M, et al. Chemical genetics strategy identifies an HCV NS5A inhibitor with a potent clinical effect. Nature 2010; 465(7294): 96-100.

[24] Watashi K, Hijikata M, Hosaka M, Yamaji M, Shimotohno K. Cyclosporin A suppresses replication of hepatitis $\mathrm{C}$ virus genome in cultured hepatocytes. Hepatology 2003; 38(5): 1282-8.

[25] Watashi K. Alisporivir, a cyclosporin derivative that selectively inhibits cyclophilin, for the treatment of HCV infection. Curr Opin Investig Drugs 2010; 11(2): 213-24.

[26] Hopkins S, Scorneaux B, Huang Z, et al. SCY-635, a novel nonimmunosuppressive analog of cyclosporine that exhibits potent inhibition of hepatitis $\mathrm{C}$ virus RNA replication in vitro. Antimicrob Agents Chemother 2010; 54(2): 660-72.

[27] Gregory MA, Bobardt M, Obeid S, et al. Preclinical characterization of naturally occurring polyketide cyclophilin inhibitors from the sanglifehrin family. Antimicrob Agents Chemother 2011; 55(5): 1975-81.

[28] Ma S, Boerner JE, TiongYip C, et al. NIM811, a cyclophilin inhibitor, exhibits potent in vitro activity against hepatitis $\mathrm{C}$ virus alone or in combination with alpha interferon. Antimicrob Agents Chemother 2006; 50(9): 2976-82.

[29] Price ER, Jin M, Lim D, Pati S, Walsh CT, McKeon FD. Cyclophilin B trafficking through the secretory pathway is altered by binding of cyclosporin A. Proc Natl Acad Sci USA 1994; 91(9): 3931-5. 
[30] Flisiak R, Horban A, Gallay P, et al. The cyclophilin inhibitor Debio-025 shows potent anti-hepatitis $\mathrm{C}$ effect in patients coinfected with hepatitis $\mathrm{C}$ and human immunodeficiency virus. Hepatol 2008; 47(3): 817-26.
[31] Chatterji U, Bobardt MD, Lim P, Gallay PA. Cyclophilin Aindependent recruitment of NS5A and NS5B into hepatitis $\mathrm{C}$ virus replication complexes. J Gen Virol 2010; 91(Pt 5): 1189-93.

(C) Garcia-Rivera et al.; Licensee Bentham Open.

This is an open access article licensed under the terms of the Creative Commons Attribution Non-Commercial License (http: //creativecommons.org/licenses/by$\mathrm{nc} / 3.0 /$ ) which permits unrestricted, non-commercial use, distribution and reproduction in any medium, provided the work is properly cited. 